\title{
Research on Efficiency Evaluation of Green Innovation
}

\author{
Kun Qian \\ School of Accounting \\ Nanjing University of Finance and Economics \\ Nanjing, China
}

\author{
Feng-yang Zhai* \\ School of Accounting \\ Nanjing University of Finance and Economics \\ Nanjing, China
}

\author{
Qing-feng Meng \\ School of Management \\ Jiangsu University \\ Zhenjiang, China
}

\begin{abstract}
The purpose of the work is to review the literature in regard to the efficiency evaluation of green innovation, and try to summarize the related existing theory and research achievements, and point out the feasible direction for the next research. By reviewing the literature, it is found that the existing researches pay more attention to the overall innovation efficiency, while the researches on the innovation efficiency in stages are less. As regard to the selection of evaluation indexes, there is no unified evaluation standard and index system. Therefore, in future research, the index system needs to be further studied to form an effective evaluation index system. In addition, there are some defects in the evaluation of green innovation efficiency with traditional DEA method. In order to improve this defect, the concept of the game among decision making units can be introduced into the study of green innovation efficiency.
\end{abstract}

Keywords-Green innovation efficiency; Data envelopment analysis; the evaluation index

\section{INTRODUCTION}

With the increasing attention of the international community to ecological issues, green innovation has become a hot issue concerned by scholars at home and abroad.

The report to the 19th national congress of the communist party of China (CPC) pointed out that China's rapid and steady economic growth has made great contributions to world economic growth. China follows the path of innovation with Chinese characteristics and implements the strategy of innovation-driven development. In recent years, scientific and technological innovation has become a sustained driving force for the sustained and healthy economic development of a region or a country. However, in China's current sustainable economic and social development, resource and environmental constraints have become one of the main bottlenecks. Faced with increasingly severe resource and environmental problems, China has put forward the concept of green development in its 13th five-year plan. According to the plan, industrial enterprises, as the main undertakers of technological innovation activities, should play a key role in $R \& D$ investment, patent application and transformation of achievements. At present, the relationship between scientific and technological economic development and environmental pollution is increasingly close. In this context, it is of practical significance to carry out green technology innovation activities and turn to green development while guiding industrial enterprises to improve the efficiency of resource utilization.

At the same time, the consciousness and initiative of implementing the concept of green development in the construction of ecological civilization have been significantly enhanced, and the concept of ecological environmental protection has become stronger and stronger. The implementation of the green innovation strategy is of great significance to enterprises. According to the existing literature, the research on green innovation and its efficiency evaluation is still in the exploration stage, the concept of green innovation has not been clearly defined, and the research perspective, measurement indicators, research methods and research results of green innovation efficiency are diverse. Therefore, this paper will sort out the research status of green innovation performance from the aspects of concept definition and evaluation index, so as to provide theoretical reference for countries and enterprises to formulate reasonable green innovation strategies and optimize the allocation of innovation resources. Finally, this paper will discuss the direction of future research in the field of green innovation.

\section{RELATED CONCEPTS OF GREEN INNOVATION}

The concept of green innovation is the product of the combination of traditional innovation theory and green ecological concept. Green innovation can also be called ecological innovation, sustainable innovation and environmental innovation.[1] The connotation understanding of the four kinds of innovation in academia is similar, but there is still no unified view on the definition of green innovation. Although the concepts of "green innovation" are slightly different from each other, they are all based on environmental improvement and can be used interchangeably.

James (1997)[2] put forward the concept of environmental innovation. Environmental innovation is a new product or process that provides value to customers and businesses with 
significantly reduced environmental impact. And then Kemp (1998)[3] put forward a similar concept. He holds the view that environmental innovation is new processes, systems and products resulting from the avoidance or reduction of environmental damage.

Hall (2003)[4] pointed out that sustainable innovation is a concept that combines sustainable development and innovation goals, and takes into account social, environmental and future generations' development factors. Besides, Hellstm (2007)[5] thought that sustainable innovation includes not only new products that reduce environmental impact, but also products that can improve other aspects of human life, such as safety and quality of life.

Frondel (2007)[6] divided ecological innovation into end treatment technology, clean production technology and environmental research and development. OCED (2010)[7] decomposed ecological innovation into ecological product innovation, ecological process innovation, ecological marketing innovation, ecological organization innovation and ecological system innovation. Eco-product innovation and Eco-process innovation depend on the development of technology, while Eco-marketing innovation, Ecoorganization innovation and Eco-system innovation depend on non-technical improvement.

Since the 21st century, the concept of green innovation has been widely put forward. Chen (2006)[8] hold the view that green innovation refers to hardware or software innovation related to green products or green processes, including those related to energy conservation, pollution prevention, waste recycling, green product design and enterprise environmental management technologies. Tseng (2012)[9] pointed out that green innovation can be divided into four categories: green product innovation, green process innovation, green technology innovation and green management innovation. Aguilera (2013)[10] pointed out that the innovation of green technology includes product design, green material, green technology, green equipment, green recycling, green packaging and so on. Driessen (2014)[11] considered that green innovation (green products) should not aim to reduce the environmental burden, but should aim to produce significant environmental benefits.

Green innovation is the primary choice for enterprises to deal with increasingly stringent environmental regulations and win market competitiveness under the operating conditions of limited resources. It depends on the effectiveness of $R \& D$ funds investment and the strengthening of the green management[12]. However, the "high input, high consumption, low output" phenomenon is still emerge in endlessly. Local brands with strong environmental protection and high added value are still rare. Therefore, it is necessary to evaluate and compare the green innovation performance of enterprises, find out the specific link of low performance, and promote the rational allocation of factor investment, improve the level of innovation management and the continuous emergence of innovative products.

\section{GREEN INNOVATION EFFICIENCY EVALUATION METHODS}

According to existing literature, there are two methods to measure the efficiency of green innovation: non-frontier analysis and frontier analysis. The non-frontier analysis includes the exponential method and regression analysis of production function, and frontier analysis includes parametric analysis and non-parametric analysis. Among them, the nonparametric analysis method constructs a minimum output possibility set that can accommodate all individual production modes according to the input and output of all decision making units in the sample, and measures the input-output efficiency based on the production possibility set. Data envelopment analysis (DEA) is a common non-parametric method. Parameter analysis on the mechanism of the unit model is higher, ask for decision making units clear functional relation between input and output, to assume the function relationship between the input and output, the error term is designed to contain to measure the efficiency of the composite structure of random items, according to the error term hypothesis distribution, using the sample data is processed by the corresponding technology, estimate the function of the parameters, the use of the function to calculate the value of efficiency. Stochastic frontier analysis (SFA)[13-15] is a common parametric method. Currently, SFA and DEA methods are widely used in the field of green innovation efficiency evaluation. Both of them measure the relative effectiveness of DMU by constructing the production frontier and using the distance function. The main difference lies in whether the production function form needs to be set.

Stochastic frontier analysis can solve the problem of multiple inputs per unit output, and the production function form needs to be set. Its advantage is that the influence of random factors can be considered, and the error term can be divided into random error term and technical inefficiency term, which can decompose the influencing factors of innovation inefficiency and consider the influence of random errors. The disadvantage is that only a single output can be measured, which is limited in application. Generally, the research is carried out by replacing the output index and using the method of measuring efficiency value from multiple angles. Tan and Chen[16] used SFA method to analyze the innovation efficiency, index elasticity and environmental factors of 28 provinces in China (except Qinghai, Xinjiang and Tibet) from 2009 to 2013.

Data envelopment analysis (DEA) can solve the problem of multi-input and multi-output efficiency. It does not need to set the production function form, but directly roots. According to the sample data, the production frontier is constructed, thus avoiding the failure of efficiency measurement results caused by improper production function form setting.However, traditional DEA models (such as DEA-CCR and DEA-BBC) do not consider the influence of random factors. The DEASBM model was first proposed by Tone (2001)[17]. This model has the characteristics of non-radial and non-angle, and puts the relaxation variables directly into the objective function, which not only solves the problem of input-output relaxation, but also solves the efficiency evaluation problem of non-expected output. Zhou used the efficiency method of 
SBM to measure $\mathrm{CO}_{2}$ emissions and the impact of environmental regulation in 30 OECD countries from 1998 to 2002. Yangjun measures the green innovation efficiency of Chinese industrial enterprises with the help of SBM model, and compares it with the traditional DEA model without considering the expected output. Yang used the super efficiency SBM model and the three-stage DEA method to calculate the green innovation efficiency of different provinces in China. Super DEA can effectively solve problems where multiple DEA is evaluated as effective. Its core is to remove the evaluated DMU from the reference set, and the super efficiency value of effective DEA is generally greater than 1 , so that effective DMU can be distinguished. Liu Jie and Fu Liping[18] used DEA C2R model and super efficiency model to calculate the technological innovation efficiency of 11 provinces and cities in eastern China. In addition, Liu and Gang used the DEA-malmquist productivity index method to evaluate the green innovation efficiency of China from 2005 to 2010 at the national, regional and provincial levels. Some scholars have introduced the concept of innovation value chain into the evaluation of green innovation efficiency, divided the innovation process of transforming ideas into results into multiple chains, and decomposed the efficiency to study the impact of the efficiency of each sub-process on the overall efficiency. The two stages in the framework of the innovation value chain cover two steps of using knowledge to realize the value of innovation. The innovation process is mainly divided into two stages: innovation input, intermediate output (input) and final output. Following this research idea, some researches divide the realization process of innovation value into two stages according to the idea of innovation value chain, namely the stage of scientific and technological research and development and the stage of market transformation. Roper and Hansen(2007)[19] divided innovation activities into two stages: product development and achievement transformation. Two-stage network DEA model can be built to measure green innovation efficiency. However, there are few studies on the efficiency of green innovation in stages, which need to be further studied.

In the research of domestic scholars, the evaluation methods of enterprise green innovation mainly focus on the following aspects: First, the traditional DEA model. Zhu Nan et al. (2015)[20] used the DEA-CCR model to analyze the fund use efficiency of Chinese financial companies. Yan Li (2012)[21] constructed a regional innovation efficiency evaluation model with DEA model, and conducted a radial empirical study on the innovation efficiency evaluation system. The traditional DEA model is only applicable to make horizontal comparison and analysis of the efficiency of decision making units with sectional data. Generally, it is suitable for enterprises to achieve the maximum economic efficiency by controlling input or output indicators under the supervision index. Second, the improvement of DEA model. Lan Hong[22], Mu Zhengshe (2014) and Zheng Liqun (2012) [23] used the DEA-BBC model to conduct an in-depth study on the comparison of enterprise efficiency and energy-saving allocation. BCC analysis method overcomes the assumption that the return on scale of CCR is constant, but the return on scale is variable, avoiding the situation that the DMU may be in the case of increasing or decreasing scale, and the efficiency of measurement is more accurate. Third, the study of DEAtotal factor productivity model. Yao Zhenghai, Liu Xiao (2016)[24], Wang Xiaoyun and Wei Qi (2016)[25] analyzed the efficiency of China's urban green economy through the DEA-malmquist model. Malmquist is also known as total factor productivity. The DEA-malmquist model is mainly applicable to the measurement of production efficiency and can be used to evaluate the efficiency of decision making units vertically. Fourth, the study of other methods. Yang Lisheng and Duan Yunlong (2007)[26] used the fuzzy comprehensive evaluation method to construct the evaluation model of green innovation ability of Chinese small and medium-sized enterprises. Li Chunhao and Su Hang (2015)[27] used DEA crossover efficiency model to analyze innovation efficiency.

\section{GREEN INNOVATION EFFICIENCY EVALUATION INDEX SYSTEM}

The evaluation of green innovation efficiency mainly carries out quantitative analysis of green innovation performance from the perspective of input and output. Below, this paper reviews the literature from the aspects of green innovation efficiency evaluation index system. Many scholars have systematically combed the evaluation index system of green innovation efficiency[29], and this paper supplemented and revised it on this basis.

First, input indexes. Human, financial and material resources are essential elements in the process of green innovation production. Manpower element is measured with the index such as input of $R \& D$ personnel and full-time equivalent of R\&D personnel normally. The commonly used indicators of financial factors are internal expenditure on R\&D internal expenditure on scientific and technological activities and expenditure on new product development. Instruments and equipment are the carriers of innovation activities, among which microelectronic control equipment original price, instrument and equipment original price are representative in measuring material input. In addition to the above three aspects, considering that green innovation aims to reduce pollution and energy consumption, energy consumption and the investment amount of enterprises in pollution control are often used to measure green innovation investment. Meanwhile, expenditure for new product development refers to the expenditure for new product research and development in the internal expenditure for enterprise science and technology activities in the reporting year.Including new product research, design, model development, testing, testing and other expenses. Expenditure for technical transformation refers to the expenditure incurred by the enterprise during the reporting year for technical transformation. In the expenditure for technological transformation, the expenditure for research and test development shall be included in and included in the expenditure for technological transformation. Both of them can be used to measure green innovation investment.

Second, the desirable output indexes. The selection of this index is divided into two stages, one is the number of patent applications, technology market turnover, new product development projects, etc. It is worth noting that the number of invention patent applications is usually selected in the research, because compared with the other two patents (utility model and 
appearance design), invention patent can better reflect the technical content and market recognition of innovation achievements. Second, the output value of new products, sales income of new products and comprehensive energy consumption rate in the stage of achievement transformation. The former two reflect the social and economic benefits brought by innovation to enterprises respectively, while the latter can reflect the energy utilization level of enterprises to some extent, namely environmental benefits. Export delivery value can also be a measure.
Third, undesirable output indexes. The traditional evaluation of innovation efficiency only considers economic benefits and ignores the impact of technological innovation on the environment. Green innovation needs to comprehensively consider the economic, environmental and social benefits brought by innovation, and introduce non-expected output to evaluate the environmental friendliness of innovation. Environmental pollution index, industrial sulfur dioxide emission and carbon emission are the most frequently cited indicators of unexpected output.

TABLE I. EFFICIENCY EVALUATION INDEX SYSTEM

\begin{tabular}{|c|c|c|}
\hline \multicolumn{3}{|r|}{ Efficiency evaluation index system } \\
\hline Index & $\begin{array}{l}\text { Classification } \\
\text { principles }\end{array}$ & Specific index name \\
\hline \multirow{4}{*}{ Input } & Human & Scientific and technological activity personnel, R\&D personnel input quantity, R\&D personnel full time equivalent, etc. \\
\hline & Financial resources & $\begin{array}{l}\text { Internal expenditure on scientific and technological activities, internal expenditure on R\&D, capital stock of research and } \\
\text { development, expenditure on new product development, expenditure on technological transformation, etc. }\end{array}$ \\
\hline & Material resources & Microelectronic control equipment cost, instrument and equipment cost, etc. \\
\hline & Energy & Energy consumption, investment in pollution control, etc. \\
\hline \multirow{2}{*}{$\begin{array}{l}\text { Desirable } \\
\text { output }\end{array}$} & $\begin{array}{l}\text { Technology research } \\
\text { phase }\end{array}$ & Patent applications and licensing, technology market turnover, new product development projects, etc. \\
\hline & $\begin{array}{l}\text { Achievement } \\
\text { commercialization }\end{array}$ & $\begin{array}{c}\text { New product output value, new product sales revenue, comprehensive energy consumption output rate, environmental } \\
\text { protection industry output value, industrial output value, the proportion of new product sales revenue in the main business } \\
\text { income, export delivery value, etc. }\end{array}$ \\
\hline $\begin{array}{l}\text { Undesirable } \\
\text { output }\end{array}$ & \multicolumn{2}{|c|}{$\begin{array}{l}\text { Energy consumption per unit of industrial added value, industrial sulfur dioxide emissions, total industrial water consumption, environmental } \\
\text { pollution index, carbon emissions, energy consumption per unit of GDP, etc. }\end{array}$} \\
\hline
\end{tabular}

\section{CONCLUSION}

At present, the research on green innovation performance in China is still in the exploratory stage, and it can be expanded from the following aspects in the future: first, the connotation of green innovation should be clarified, and the evaluation standard and index system of green innovation efficiency in specific industries should be formulated differently. Secondly, relevant research on innovation efficiency is carried out from the perspective of stages and green supply chain, so as to provide scientific basis for more detailed innovation policy making. In addition, DEA and its related extension methods provide a good tool for the evaluation of green innovation efficiency. However, the principle of DEA method belongs to the idea of selfevaluation and ignores the competition and cooperation between DMU. Therefore, it is very necessary to introduce the game DEA theory into the field of green innovation efficiency evaluation. The existing research still has the following problems: first, there is no targeted evaluation index system for different industries. Second, there are more researches on the overall efficiency of green innovation, while fewer researches on the efficiency in stages.

\section{ACKNOWLEDGMENT}

This research was financially supported by the National Natural Science Foundation of China (Grant NO. 71602083, 71671080, 71501084, 71571099) and Social Science Foundation of Ministry of Education of China (Grant NO.14YJCZH116).

\section{REFERENCES}

[1] Bernauer T, Engel S, Kammerer D, et al. Explaining Green Innovation: Ten Years after Porter's Win-Win Proposition: How to Study the Effects of Regulation on Corporate Environmental Innovation?[J]. Social Science Electronic Publishing.

[2] James D G. Imidacloprid increases egg production in Amblyseius victoriensis (Acari: Phytoseiidae)[J]. Experimental \& Applied Acarology, 1997, 21(2):75-82.

[3] Kemp. Propositions and Reasoning in Russell and Frege [J]. Pacific Philosophical Quarterly, 1998, 79(3):218-235

[4] A. J. Hall, O. I. Kalantzi, G. O. Thomas. Polybrominated diphenyl ethers (PBDEs) in grey seals during their first year of life--are they thyroid hormone endocrine disrupters?[J]. Environmental Pollution, 2003, 126(1):29-37.

[5] Tomas Hellström. Dimensions of environmentally sustainable innovation: the structure of eco-innovation concepts[J]. Sustainable Development, 2007, 15(3):148-159.

[6] Mirata M, Emtairah T. Industrial symbiosis networks and the contribution to environmental innovation[J]. Journal of Cleaner Production, 2005, 13(10):993-1002.

[7] OCED. Sustainable Manufacturing and Eco-Innovation. [J].2009

[8] Min Chen, Taekyoung Kwon, Yanghee Choi. Energy-efficient differentiated directed diffusion (EDDD) in wireless sensor networks[M].Elsevier Science Publishers B. V., 2006.

[9] Chun Ping Lin, Jo Ming Tseng. Green technology for improving process manufacturing design and storage management of organic peroxide[J]. Chemical Engineering Journal, 2012, 180(6):284-292

[10] J. Aguilera-Caracuel, N. Ortiz-De-Mandojana. Green Innovation and Financial Performance: An Institutional Approach[J]. Organization \& Environment, 2013, 26(4):365-385.

[11] Miriam Weber, Peter P. J. Driessen , Hens A. C. Runhaar. Evaluating environmental policy instruments mixes; a methodology illustrated by noise policy in the Netherlands[J]. Journal of Environmental Planning \& Management, 2014, 57(9):1381-1397. 
[12] Shu C, Zhou K Z, Xiao Y, et al. How Green Management Influences Product Innovation in China: The Role of Institutional Benefits[J]. JOURNAL OF BUSINESS ETHICS.

[13] Aigner DJ, Lovell CAK, Schmidt P.Formulation and Estimation of Stochastic Frontier Production Function Models[J]. Journal of Econometrics, 1977, 6(1):21-37.

[14] Blattel-Mink, B.Innovation Towards Sustainable Economy-the Integration of Economy and Ecology in Companies[J].Sustainable Development.1998, 6(2):49-58.

[15] Beise-Zee, M.\&.Rennings, K.Lead Markets and Regulation: A RAM work for Analyzing the Internationl Diffusion of Environmental Innovation[J].Ecological Economics, 2005, 52(1):5-17.

[16] Tan X D, Chen Y W. Evaluation of innovation efficiency of pharmaceutical manufacturing industry in China based on SFA[J]. Chinese Journal of New Drugs, 2016.

[17] Tone K. A slacks-based measure of efficiency in data envelopment analysis[J]. European Journal of Operational Research, 2001, 130(3):498-509.

[18] Jie L J L, Liping F L F. Regional Innovation Efficiency Study Based on Super-Efficiency Evaluation Mode - Technological Innovation Efficiency Analysis of 11 Provinces and Cities in Eastern China[C]// International Conference on Environmental Science \& Information Application Technology. IEEE Computer Society, 2009.

[19] Hansen M T, Birkinshaw J. The innovation value chain [J]. Harvard Business R eview, 2007, 85( 6) : $121-130$.

[20] Zhu Nan, Tan Debin. Research on capital use efficiency, dynamic

[21] change and influencing factors of Chinese financial companies - an empirical analysis based on DEA method [J]. Financial Research, 2015, (1):177-192.
[22] Yan Li. An empirical study on the evaluation index system of regional innovation efficiency in China [J]. Management world, 2012, (5):174175.

[23] Lan Hong, Mu Zhengshe. Performance evaluation and improvement direction of China's rural credit cooperatives after reform - an empirical study based on three-stage DEA model and BCC analysis [J]. Finance research, 2014, (4):63-82.

[24] Zheng Liqun. Apportionment of carbon emission reduction responsibilities among provinces and regions in China - a study based on zero-sum income DEA model [J]. Resources science, 2012, (11):2087-2096.

[25] Yao Zhenghai, Liu Xiao. Research on innovation efficiency evaluation of China's high-tech service industry [J]. Economic issues, 2016, (9):8286.

[26] Wang Xiaoyun, Wei Qi. Comprehensive measure and spatio-temporal differentiation of urban green economy efficiency in China - based on dea-bcc and Malmquist model [J]. Ecological economy, 2016, (3):40-45.

[27] Yang Lisheng, Duan Yunlong. Research on enterprise green innovation ability based on fuzzy comprehensive evaluation - small and mediumsized enterprises' green innovation ability evaluation and application [J]. Journal of Yunnan university for nationalities: natural science edition, 2007, (16):197-201.

[28] Li Chunhao, Su Hang. DEA cross efficiency evaluation model based on rational decision making unit reference solution strategy [J]. China management science, 2015, (23):116-122.

[29] Renqiao Xiao, Juan Ding, Li Qian. Research review on green innovation performance evaluation [J]. Journal of guizhou university of finance and economics, 2017(2). 